The art of medicine, like those of love and motherhood, is preached more often than practiced. Nowhere is it expressed better than by the physician's compassionate, careful approach to the patient to find out "where it hurts." Just as it has through the ages, the $\mathrm{H}$ and $\mathrm{P}$ remains the most reliable clinical investigative tool.

GEORGE W. NORTHUP, D.O., FAAO

\section{Rationing health care: Solution to increasing medical costs?}

The urgency to cut health care costs has resulted in many proposals. Perhaps one of the most disturbing was suggested at a recent joint ethics meeting of the American Medical Association and The Hastings Center held in New Orleans. (The Hastings Center, located in Briar Cliff, New York, examines ethical issues facing the scientific and medical communities.) According to a report of the meeting in the May 28, 1986, issue of Medical Tribune, Dr. William B. Schwartz, professor of medicine at Tufts University and author of The painful prescription, stated that while the rationing of medical care may be difficult to accept, it may be the only way to contain health costs. Professor Schwartz indicated that advances in medical treatments and technology over the past decade were major contributors to increased health care expenses. Further, he claimed that present efforts, such as health maintenance organizations and diagnosis-related groups, decreasing the number of ancillary tests, and ridding waste and inefficiency, would result in only a 20 -percent reduction in the base cost of medical care.

This rationing approach was challenged by Dr. Norman Levinsky, Wade professor and chairman of medicine at Boston University School of Medicine. He warned that the basis of our health care system would become focused on the cost to society at the expense of the individual's benefits. This would further magnify the inequality of social class, expand the "blame the victim" phenomenon, and lead to the labeling of an "unworthy class" of people. In place of rationing, Dr. Levinsky suggested that certain developments in the past, such as eradication of smallpox, have indicated that "true future technology" and more effective prevention programs are better means for reducing costs.

As mentioned in these editorial pages and in other journals, patient cooperation is essential to eliminate smoking, obesity, over-indulgence in alcohol, and drug abuse-all major contributors to health care expenses. Rationing of medical care is not going to effect a change of direction by the consumer. It will merely put him or her at greater risk.

It is an obvious truisim that the practice of defensive medicine increases the health care costs of the nation. Until more satisfactory methods are developed to reduce the amounts awarded in frivolous malpractice suits, higher than necessary health care costs will continue.

All of medicine must stand up and be counted in the onrushing clash between quality medical care and the need to cut financial expenditures. Certainly there are many steps that can be taken, particularly by the public sector, to reduce these expenses. Rationing must not be the answer.

GEORGE W. NORTHUP, D.O., FAAO

\section{$\overline{\text { editorial comment }}$}

At some future date, a drug that will block brain injury in heart attack and stroke victims without damaging healthy brain cells may become a reality. This optimistic prediction is based on new findings on the nature of brain damage by researchers at The Johns Hopkins Medical Institutions.

Previously, oxygen deprivation to the brain for more than 5 minutes was thought to destroy nerve cells there. However, it now appears that the process is more gradual. It also has been found that anoxia triggers a cascade of biochemical reactions within cells. Johns Hopkins' cell and animal experimentation centers on the amino acid glutamate, which usually is present in the brain in minute amounts. Released by specific nerve cells, glutamate binds with receptors or other nerve cells to cause normal nerve excitation. Effects triggered by the stress of anoxia leave nerve cells comparatively awash in glutamate, which results in a flow of calcium ions into the nerve cells. That, in turn, activates enzymes that cannibalize the cell and initiates other changes leading to cell death. Therefore, a drug designed to interrupt the cascade could slow or block brain damage.

Johns Hopkins' researchers have also demonstrated that certain drugs, such as flunarizine, that block calcium uptake can reduce brain damage in rats by about 50 percent. They also are testing drugs that block the progress of cell death at the site of one subtype of glutamate receptor in the brain. Although a number of these drugs have been found to prevent damage in isolated rat brains, drugs with fewer side effects, more suitable for humans, must be found before clinical trials can be conducted. 